\title{
Edítoríal.
}

\section{THE NATURE OF DESIRE.}

Trougi the psychologist has devoted much attention to the analysis of conscious states by the method of introspection, there is a diversity of opinion as to the ultimate constituents, stuff, ingredients, or elements of which mind is composed. Thus, one group of psychologists regards sensation as the one, and only basic form of mind; another would add elements known as simple affections; and a third would recognize in addition another element, to which such terms as will, conation, striving, wish, desire, and appetite have been applied. Actually the divergence of opinion is perhaps not so great as might be supposed. To some extent it results from the tendency of certain psychologists to consider mind in terms of content or structure, whilst others emphasize its function or behaviour. Those who would exclude conative elements as ingredients of consciousness do not, of course, deny the existence of anything corresponding to the will of popular belief; but they fail to discover any element like that of sensation which corresponds to the will. This elusive and intangible quality is, in fact, the essence of life and mind. It resists introspective analysis, but it is nevertheless just that fundamental characteristic which distinguishes living organisms from inert matter.

It is perhaps true to say that it is upon this intangible and unanalyzable quality of mind that the structure of modern psychology is based. Briefly, the organism is considered from the dynamic point of view, and the 'wish' has now replaced the sensation as the unit of psychology. Various influences have operated in bringing about this change of viewpoint, and the most striking of these is the work of Freud in the field of clinical psychology, where it has been shown that psychic disturbances are not to be located in the intellectual functions, but rather in the realms of feeling and desire. It has to be recognized, however, that, great as Freud's influence has been, his fundamental assumptions have been subjected to no small amount of criticism, and that they have on the whole failed to gain acceptance. Some of these criticisms are trivial, unimportant, and often based upon prejudice; but others are important, and emanate from those whose opinions carry a great deal of weight. In the second category are to be included certain criticisms made by 
Mr. Bertrand Russell, who is deservedly reckoned as one of our most eminent of contemporary philosophers, in his recent volume, The Analysis of Mind. Reference may here be made more particularly to his views on the nature of desire.

Mr. Russell recognizes that the general theories of psycho-analysis are of much importance for the theoretical analysis of mind, because it has been clearly established by Freud that a man's actions and beliefs may be wholly dominated by a desire of which he is totally unconscious. In other words, it has been shown that consciousness is not necessarily a characteristic of phenomena to which the term mental may be applied. Granting, however, the value of Freud's researches, Mr. Russell makes the following critical observations : "Freud and his followers, though they have demonstrated beyond dispute the immense importance of 'unconscious' desires in determining our actions and beliefs, have not attempted the task of telling us what an 'unconscious' desire actually is, and have thus invested their doctrines with an air of mystery and mythology which forms a large part of its popular attractions. They speak always as though it were more normal for a desire to be conscious, and as though a positive cause had to be assigned for its being unconscious. Thus the unconscious becomes a sort of underground prisoner, living in a dungeon, breaking in at long intervals upon our daylight respectability with dark groans and maledictions and strange atavistic lusts."

Similar criticisms have frequently been made by psychologists and others who are accustomed to express themselves in scientific rather than popular language. It is felt that Freud's nomenclature and descriptions are based largely upon metaphors which tend to give rise to the impression that the new facts which have been discovered need no further elucidation; and it is considered that such facts should be capable of being understood without assuming the existence of a mythical entity endowed with anthropomorphic qualities. These are valid criticisms, and it is obviously undesirable to personify so intangible a concept as the 'wish' or desire if it can be avoided. A science begins to progress when its terminology is clearly defined, and as that is what Mr. Russell endeavours to do in respect to the term desire, his work is not merely critical but definitely constructive.

Mr. Russell develops the view that desire is to be understood as a causal law of our actions, and not as something existing in our minds. He finds that the study of animals is in many ways the best preparation for the study of desire. "A hungry animal is restless until-it finds food; then it is quiescent. The thing which will bring a restless condition to an end is said to be what is desired. . . . The characteristic mark by which we recognize a series of actions which display hunger is not the animal's mental state, which we cannot 
observe, but something in its bodily behaviour; it is this observahle trait in the bodily behaviour that I . . call hunger, not some possibly mythical and certainly unknowable ingredient of the animal's mind." A consideration of desire as exhibited in animals makes it clear (and this is the essence of Mr. Russell's theory) that unconscious desire is the natural and primitive form of desire. (A pure example would be a hen sitting on eggs for the first time.) Such a view of the nature of desire would seem to differ fundamentally from those of Freud, because it renders it unnecessary to assign a positive cause for the existence of an unconscious desire. The following quotations indicate the view in the mind of the author: "What is called an 'unconscious' desire is merely a causal law of our behaviour (cf. Hart, The Psychology of Insanity), namely, that we remain restlessly active until a certain state of affairs is realized, when we achieve temporary equilibrium. If we know beforehand what this state of affairs is, our desire is conscious; if not, unconscious. The unconscious desire is not something existing, but merely a tendency to a certain behaviour; it has exactly the same status as a force in dynamics. . . . It is not necessary to suppose, as Freud seems to do, that every unconscious wish was once conscious, and was then, in his terminology, 'repressed because we disapproved of it'. On the contrary, we shall suppose that, although Freudian 'repression' undoubtedly occurs and is important, it is not the usual reason for unconsciousness of our wishes. The usual reason is merely that wishes are all, to begin with, unconscious, and only become known when they are actively noticed."

Here then is a theory of desire which deserves serious consideration, because it does much to dissipate the atmosphere of mystery. which pervades current conceptions of the 'unconscious'. The theory has, furthermore, the advantage of being thoroughly biological, because it is based upon the view that man has developed out of animals, and that there is no serious gap between him and the amœba. This is definitely the case in respect to structure and behaviour, and it is probably so in the sphere of mind. 